\title{
Development of guidance for the management of the toe of coastal defence structures
}

\section{Michael Wallis ${ }^{1}$, Richard Whitehouse ${ }^{1}$ and Nick Lyness ${ }^{2}$}

${ }^{1}$ HR Wallingford, Howbery Park, Wallingford, Oxfordshire OX10 8BA, UK

2 Environment Agency, Blandford Forum, UK

Presented at Coasts, Marine Structures and Breakwaters 2009 Conference, EICC, Scotland, 16-18 September 2009

\section{Introduction}

Beach lowering and the effects of scour in front of coastal defences and erosion protection structures are recognised as a principle cause of their failure including collapse/breaching and washing out of fill materials. Both localised scour and more widespread beach lowering can lead to undermining of the Toe (see Figure 1 for definition). This can promote structural instability and result in partial or total collapse with subsequent reduction in, or loss of performance for flood defence or erosion protection.

Lowering of the 'ground levels' in front of seawalls, revetments or other coastal structures is a common phenomenon not only in the U.K. but also around the world. Toe scour is a serious and costly problem moreover, it is one which is not limited to any particular coastal environment or to any particular type of defence structure. The prevention of, design for, and management of beach lowering and scour at the Toe of coastal structures is an important factor in the management of those structures.

Understanding, designing for and managing toe scour at coastal structures therefore is a key issue for coastal managers, designers and engineers. To date there has been no guidance available tailored specifically to meet these needs. Recognising this, the Defra/ Environment Agency Flood and Coastal Risk Management programme commissioned the development of guidance on the management of the Toe of coastal structures in 2008 (Toe Scour Guide).

The guide draws together recent key research and development work on beach lowering and scour including 'Understanding the Lowering of Beaches in Front of Coastal Defence Structures' (Sutherland et al, 2006, 2008). It is also integrating work on performance and reliability of coastal structures developed through the Performance-based Asset Management Project (PAMS) including performance analysis and asset inspection methods. This paper reflects on and highlights some of the developments made in the preparation of the guide. 


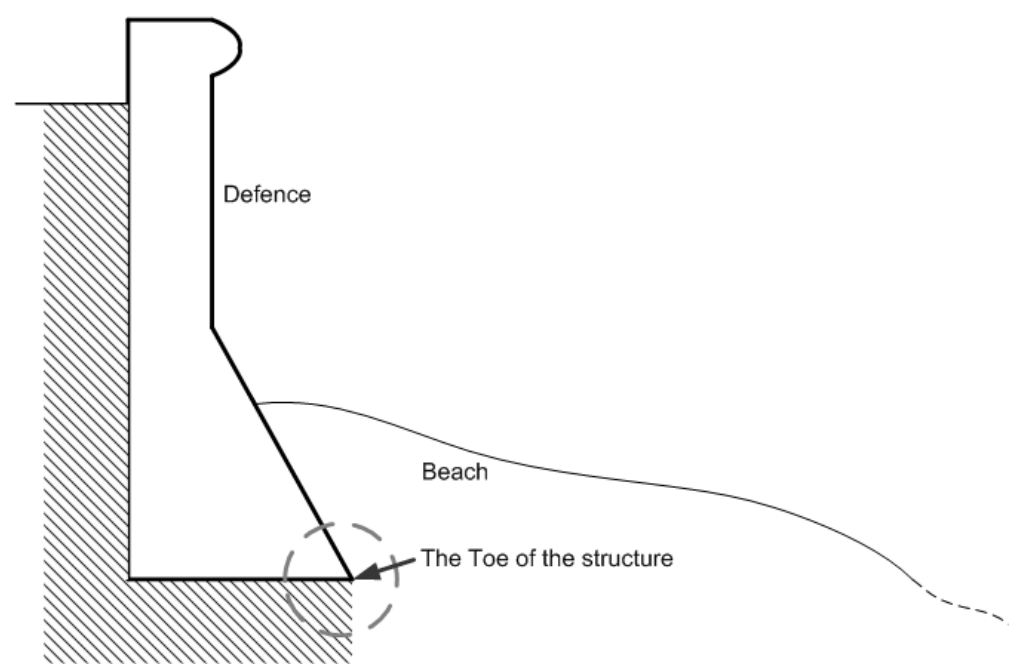

Figure 1: Definition of the toe of the defence structure and the level of the beach (a variable quantity)

\section{Risk and Asset management}

Society demands increased reliability and safety in regard to assets used to protect it from natural hazards. Increasingly, politicians, businesses and decision-makers require that risks associated with civil engineering structures, especially infrastructure, are quantified. Risk can be evaluated by involving multi-disciplinary competences including engineers, geoscientists and statisticians to carry out reliability analyses and provide risk estimates that can assist in decision-making. The derivation of risk requires the use of probabilistic approaches because these provide a rational framework for taking into account uncertainties.

Managing risk first involves the identification, analysis and assessment of those risks to enable informed decisions to be made on whether and how they should be controlled or mitigated. This approach to risk is necessary because some factors are uncertain and others cannot be controlled. Risk is evaluated by identifying the hazards or 'sources', evaluating the likelihood of a failure of controls or defences, evaluating the potential consequences of failure, and then assessing the results for acceptability. The treatment of risk is the process of selecting and implementing measures for managing identified risks. Risk treatment may involve simply monitoring low risks or developing mitigation plans for addressing higher risks. Risk mitigation is achieved by either reducing the likelihood of an occurrence, or its consequences, or both. Thus the management of defence or protection assets is a key component in the treatment and mitigation of flood and erosion risks.

Figure 2 illustrates a simplified conceptual cycle of asset management for the Toe of coastal defence structures within which the management of risk is implicit. This paper is primarily concerned with the top and right hand elements of the cycle, namely the definition and understanding of the risks, predictive analyses and monitoring approaches for sediment levels at the Toe. It also seeks to show how this information and various methods can be used together to assist coastal managers in their decision-making and planning regarding when they might need to consider remedial options or to intervene. 


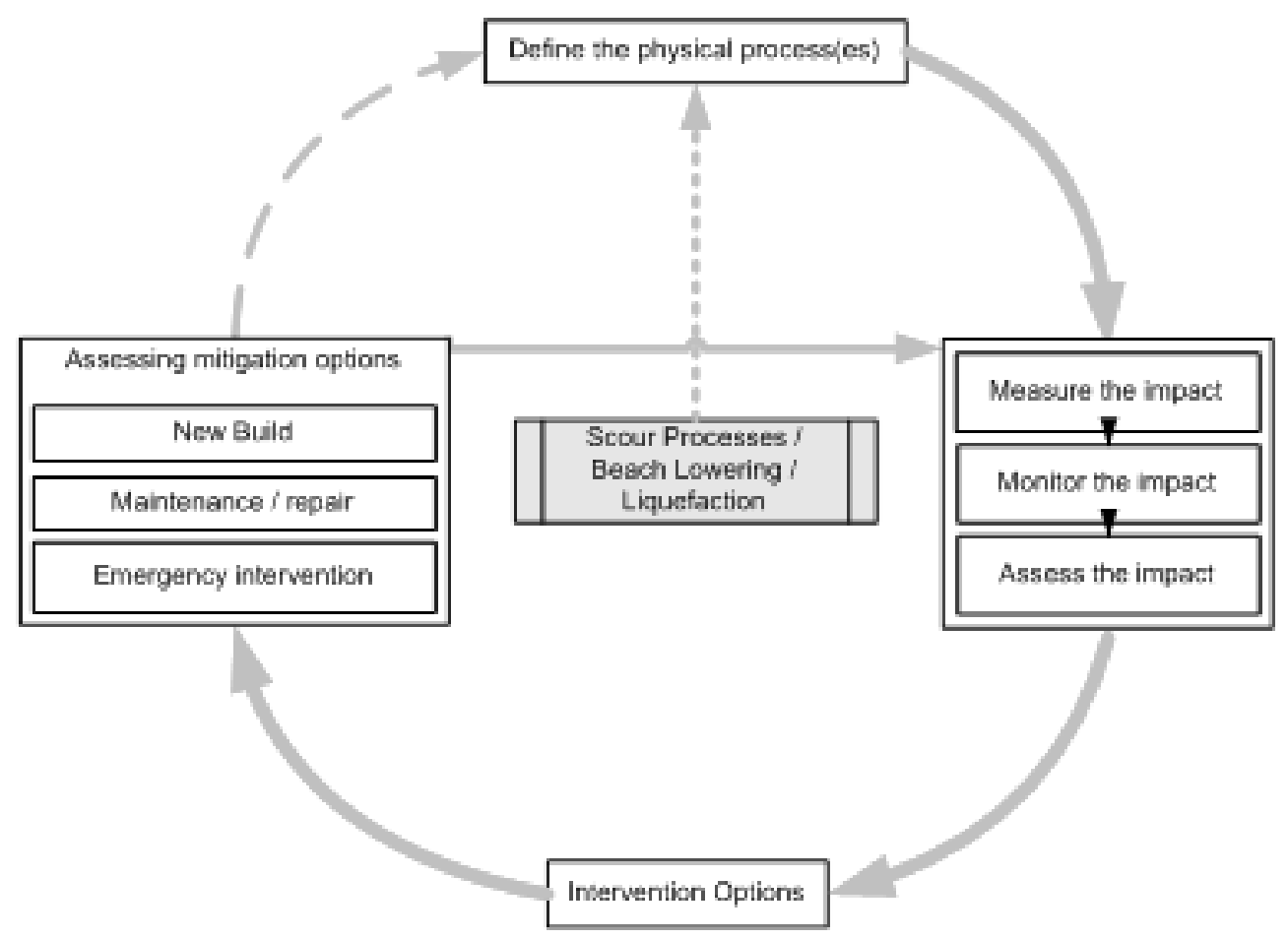

\section{Risks associated with the failure of the Toe of defence structures}

Both localised scour and the more widespread beach lowering can lead to problems with coastal structures. An example of this is shown in Figure 3 where there was failure of the Toe piling and structure over a $50 \mathrm{~m}$ length of frontage. The failure occurred due to a general lowering of the sand beach as well as scour in two storms, a prolonged north-easterly storm in November 1999 and a shorter storm in April 2000. Remedial works were subsequently implemented (Patterson et al, 2004).

The ongoing occurrence of scour related problems supports the findings of a comprehensive survey published over twenty years ago by CIRIA (1986). That survey concluded scour at the Toe of coastal defence/protection structures represented the most serious form of damage to seawalls in the UK. It directly accounted for $12 \%$ of the seawall failure case histories studied and was linked indirectly to a further $5 \%$ of cases. Similar conclusions were drawn in the USA for rubble-mound structures (Markle, 1986). A number of causes of failure were referred to including loss of supporting beach material from in front of a coastal defence structure, the washing out or winnowing of granular 'fill' from behind the face of the structure, and a gradual dislocation of the rubble mound or blockwork foundation;

Toe structures are a key component in coastal defence design as they are built, and often 'retrospectively' installed, to stabilise existing structures and prevent or mitigate the risk of failure of the original defence structure. Toe structures are however subject to the same physical processes as the original or 'parent' 
structure - i.e. removal of foundation elements and passive resistance through beach lowering and scour, and the impact forces of waves. The Toe highlighted in Figure 1 is the physical Toe of the structure but the intersection of the beach level and the structure form a 'visible' Toe, i.e. what an inspector would see. The physical Toe of the structure may remain buried beneath beach sediment year on year. The level of the beach will vary and hence the depth of burial of the foundation at any time is variable. As the beach level lowers the position of the interface of high variability may move closer to the physical Toe of the structure. To evaluate the risk an understanding of the physical factors and processes is required. The impact of the change in beach levels on the structure can be encapsulated in the concept of a "trigger" level.

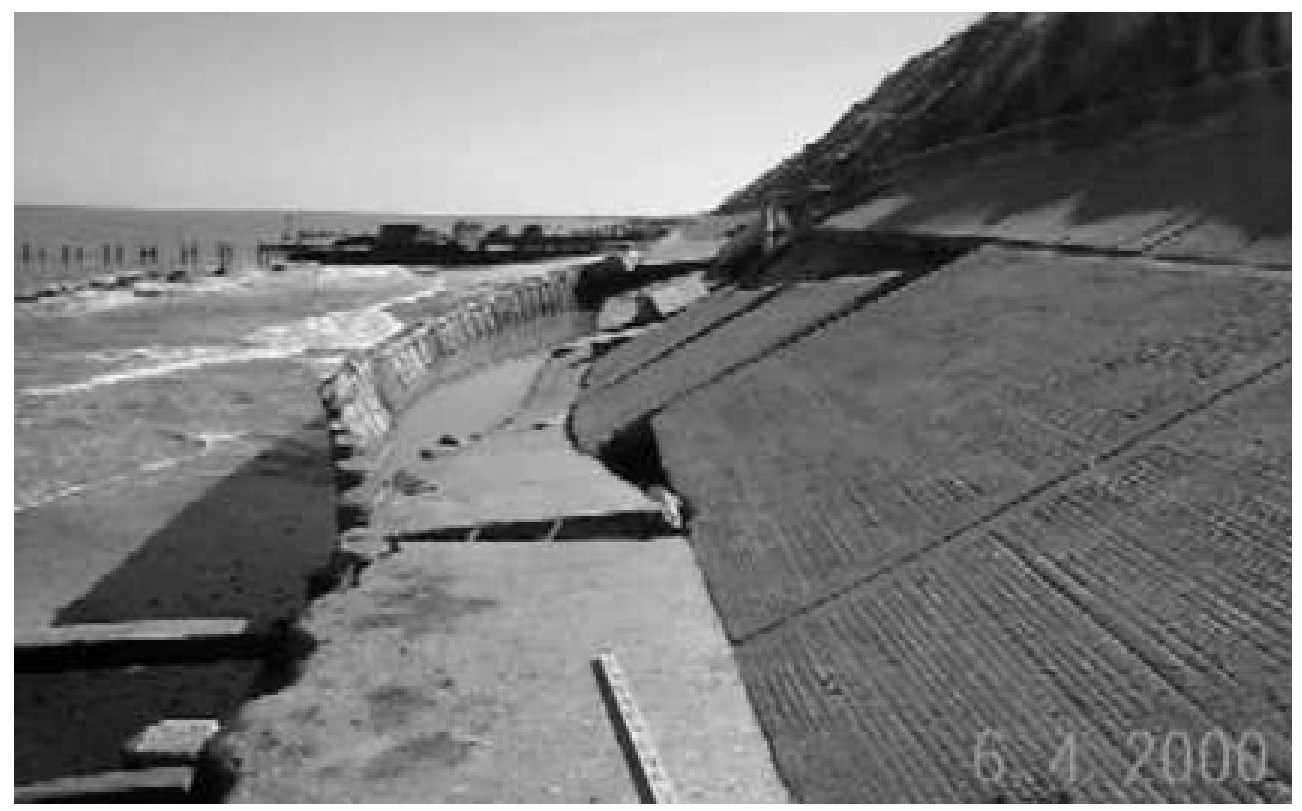

Figure 3: Structure collapse at Corton (April 2000) (photograph courtesy of Waveney District Council)

\section{Trigger levels}

An important concept in beach management is the criticality of beach levels at the Toe of coastal structures. The potential for failure through sliding and overturning is of particular concern with regards to old seawall structures, the following being relevant factors:

- Factors of safety used in former times (e.g. $19^{\text {th }}$ century) would not necessarily have achieved current day standards;

- Beach lowering (if prevalent) over many years or decades of service; and,

- Possible scour induced by the presence of the vertical wall itself.

Analytically, the problem results from an imbalance of loads across the structure. Figure 4 illustrates a simple case in which the loads are confined to geotechnical and hydrostatic pressures on a gravity wall; the principal forces are:

- $\mathrm{P}_{\mathrm{a}}=$ sum of active geotechnical and hydrostatic forces, i.e. on the landward side, tending to push the seawall outwards; 
- $\mathrm{P}_{\mathrm{p}}=$ sum of passive geotechnical and hydrostatic forces, i.e. on the seaward side, tending to resist the active pressure and movement; and,

- $\mathrm{F}_{\mathrm{b}}=$ the friction on the base of the wall, also tending to resist the active movement of the wall (equals the weight of the wall (Mw) multiplied by the friction coefficient of the wall base ( $\mathrm{Lw}$ ) on the ground beneath).

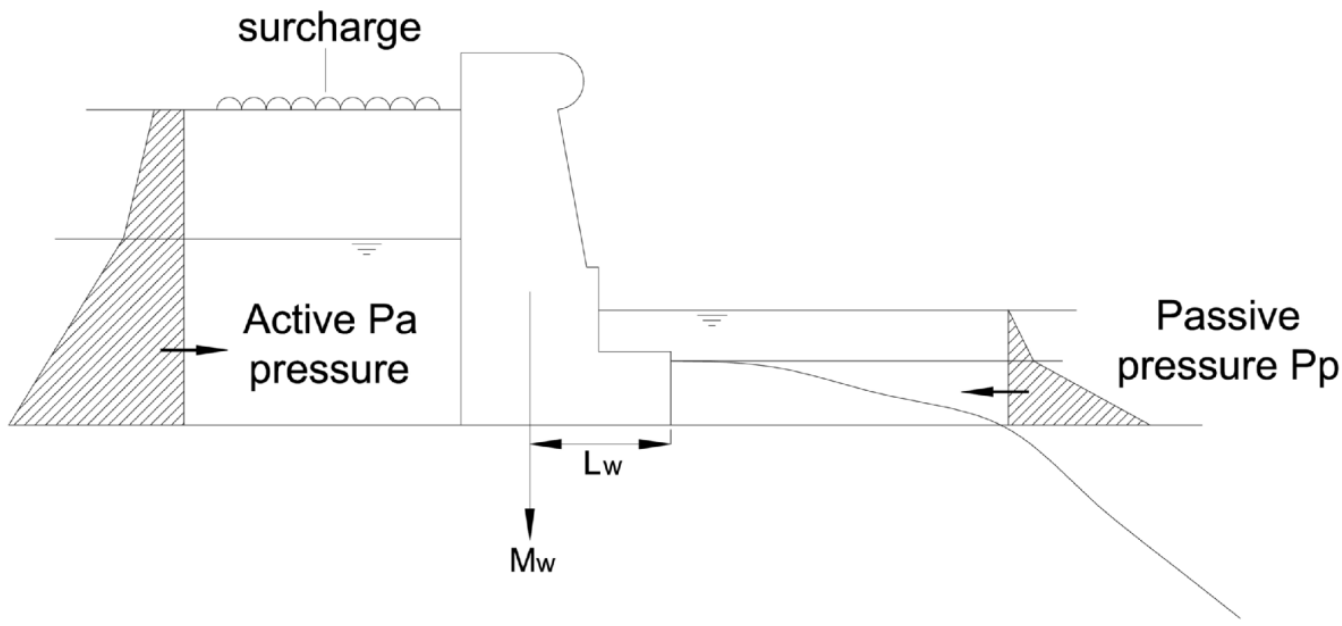

Figure 4: Simplified forces on a gravity wall

However, over time beach sediment levels increase and decrease - they are variable, thus the passive geotechnical as well as the hydrostatic forces $\left(P_{p}\right)$ are variable. Effective management should aim to understand and act upon this variation should it extend and persist beyond certain limits in the future - either too much sediment, if this is a problem - or, more typically, too little sediment. The calculation of active and passive pressures can be found in most standard text books on geotechnical engineering, e.g. Scott (1969), and is well described in the Piling Handbook (2005). This is a comprehensive subject in its own right which is dealt with specifically and at some length by other texts; as such the details are not reiterated here.

The examination of statistics on mean beach levels in relation to the Toe of a structure together with prediction methods and structure geometry information (level of the structure Toe) can be combined to provide information that the asset manager can use to determine the physical limits and timescale within which intervention options should be considered (i.e. beach renourishment, remedial defence works, decommissioning etc). This concept is illustrated in Figure 5.

As well as the general trend and statistics of beach level indicated in Figure 5 the potential local scour needs to be taken into account as the local bed level at the wall may drop below the critical level during a storm. 


\section{Predictive Analyses}

There are three key predictive measures that the management of Toe structures should consider. These are:

- Predicting the lowering of beach levels;

- Predicting sediment scour at the Toe ${ }^{1}$; and

- Predicting deterioration of the structure and failure (not included in the present discussion).

\subsection{Predicting beach lowering}

The performance of a beach largely depends on the volume of material present and the limits to its plan and profile changes - influenced particularly by sediment control structures within it (e.g. groynes). Where there is a continuing net loss of sediment, then beach recovery is an issue. In general, failure is a result of depletion in the volume of the beach through increased longshore and / or cross shore transport of beach sediment, or, a reduction in supply of sediment onto the frontage. Beach levels are constantly changing although trends of depletion or accretion are generally gradual (long term), however significant erosion and lowering can occur during 'one-off' storm events.

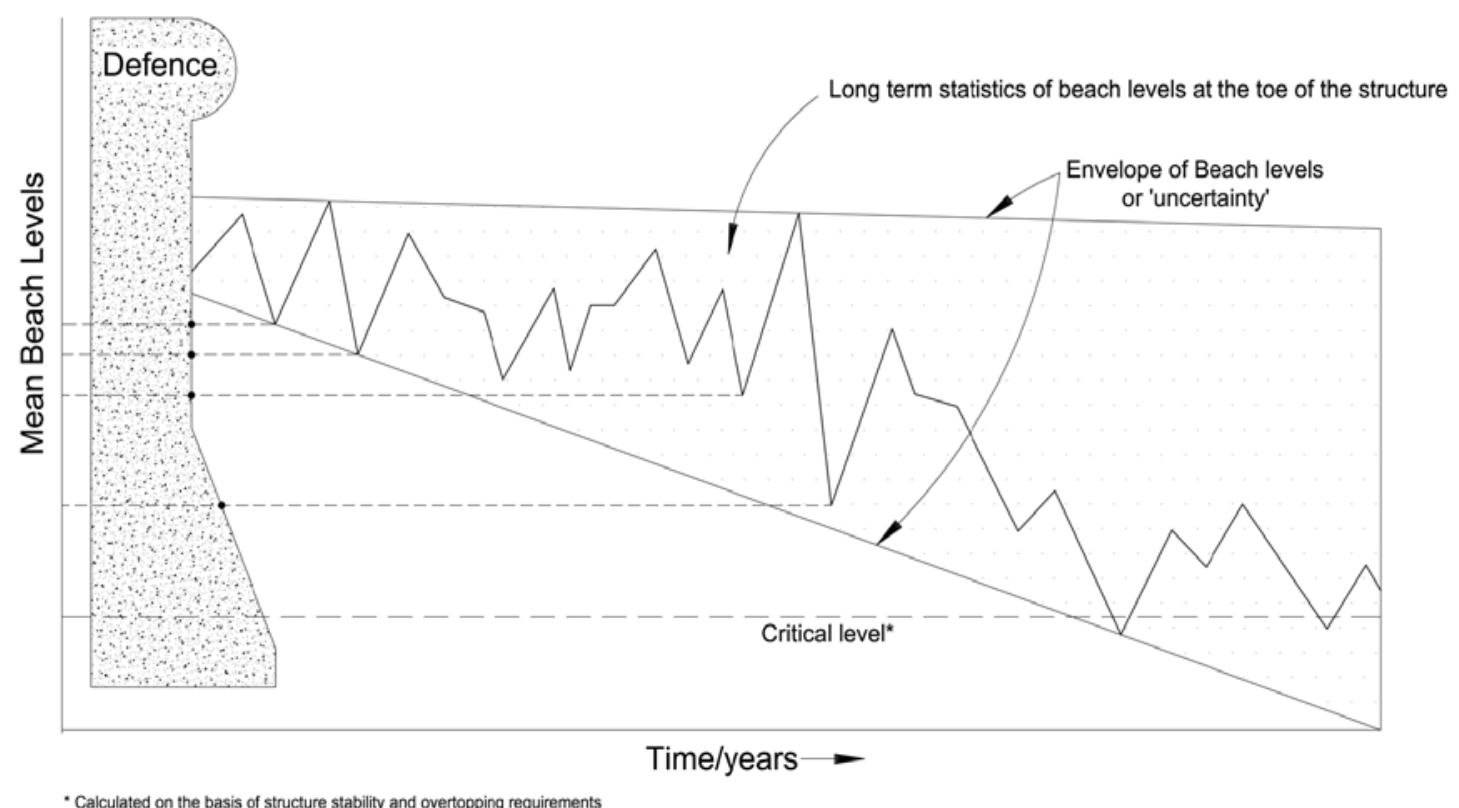

Figure 5: Schematic diagram showing the development of beach levels in time and the concept of a critical level for foundation performance based on asset management requirements

The variations in beach levels near coastal structures at a range of time scales from one tide to the order of a year are the accumulation of residual changes in level that occur during each tide. However, it is common to find beach levels lower in winter than in summer, due to the increased occurrence and severity of storms

${ }^{1}$ Localised sediment scour at the Toe of a structure is a different physical process to beach lowering, although partly dependent upon that of broader scale beach lowering. 
during winter. It also follows that beach levels may show a greater variation about their seasonal mean during winter (Sutherland et al, 2008).

A range of advanced linear and nonlinear data analysis methods can be used to analyse the long-term prediction of beaches (Larson et al., 2003, HR Wallingford 2008c). Data based analysis will become more powerful as the amount of regularly-sampled and accurate data collected, stored and managed by organised regional coastal observatories and others increases. The evaluation of profile data may be supplemented by the results from process-based numerical models of cross-shore beach evolution (e.g. van Rijn et al., 2003).

One dilemma the analyst faces is what prediction 'horizon' can be expected when extrapolating beach level time series data. Analysis of beach monitoring data from Lincolnshire (HR Wallingford, 2008a, Sutherland et $a l$, 2008) illustrates that the predictive ability of a straight line fit from more than 10 years of data is limited to a few years beyond the end of the dataset, but this should be sufficient for the purposes of supporting annual inspection combined with predictive modelling (that is the assumption made here). An indicative per annum allowance for beach lowering based on data provides a guide to potential beach lowering rates and informs the design and maintenance of coastal defences. The indicative allowances for beach lowering can be applied in the same way as, say, indicative allowances for sea level rise.

\subsection{Predicting sediment scour at the Toe}

The development of toe scour is a dynamic process, highly dependent on the water level at the wall and the incident wave conditions. In areas of varying tidal range and wave climate, the development of a scour hole will be an episodic process with periods of erosion followed by infilling, and perhaps even general accretion of the bed (Powell and Lowe, 1994). The scour hole itself may therefore be a short-lived feature with no obvious evidence of its extent, or perhaps even its existence after a storm has declined and infilling has taken place as the tide recedes. This means that the profile seen before and after the storm may be quite similar in consecutive beach profiles taken at low water. Hence, there is a need to be able to predict the maximum depth of the scour hole during storms, as well as the more widespread and longer-term processes that cause the lowering of beach/shore-platforms. This is important both in the design stage of planning a coastal structure, and in its subsequent monitoring if the risk to the future integrity of the wall is to be fully understood and timely remedial action undertaken.

As storm event scour is frequently short-lived, the typical twice-yearly beach profile monitoring carried out around the English coast is unlikely to capture a major scour event but can indicate the way in which the beach is evolving and record seasonal variations (summer and winter) at the seawall. Indeed, the evidence supplied by data from bespoke scour monitors (Sutherland et al, 2006) suggests that a significant amount of a scour hole can fill in within a few hours of the peak of a storm. Therefore even regular beach profiling with a spacing of a few weeks, supported by profiles collected within a day or two of each large storm may not be enough to capture the transient phenomenon of toe scour in the field. So a combined evaluation of beach level trends and scour prediction is an appropriate way forward.

\subsection{Prediction of toe scour depths at vertical seawalls with sand beaches}

A rule of thumb for vertical seawalls is that the scour depth is equivalent to the (unbroken) significant wave height $H_{s}$ (Whitehouse, 1998). As an improvement on this (Sutherland et al, 2008; HR Wallingford, 2008b) recommended the use of a conservative predictor of scour depths which may be used in the absence of site- 
specific information on beach slope. It is reproduced as Equation (1) with $H_{s}$ as the commonly used scaling parameter for predicting scour depth:

$$
\frac{S_{t \max }}{H_{s}}=4.5 e^{-8 \pi\left(h_{t} / L_{m}+0.01\right)}\left(1-e^{-6 \pi\left(h_{t} / L_{m}+0.01\right)}\right)
$$

where:

$S_{\text {tmax }}$ is the maximum toe scour depth $(\mathrm{m})$;

$h_{t}$ is the water depth above the sediment level at the Toe of the structure $(\mathrm{m})$; and

$L_{m}=g T_{m}^{2} / 2 \pi$ is the linear theory wavelength based on acceleration due to gravity $g$ (assumed to be $9.81 \mathrm{~m} / \mathrm{s}^{2}$ ) and mean wave period $T_{m}(\mathrm{~s})$.

The equation is plotted with data in Figure 6 . The range of validity of Equation (1) is given in the [ ] brackets in terms of $h_{t}$ and $L_{m}$. When this equation was tested by validating laboratory tests with field data from two UK sites, Blackpool and Southbourne, it was found that the field data generally had lower scour depths than the laboratory data. This is believed to have been caused by the fact that wave height, wave period and scour depth were only measured at a single tidal state in the laboratory. The field data was collected in situations with constantly varying water levels and wave heights. However, the upper limits of the field observations confirm the laboratory data and envelope curve of Equation (1).

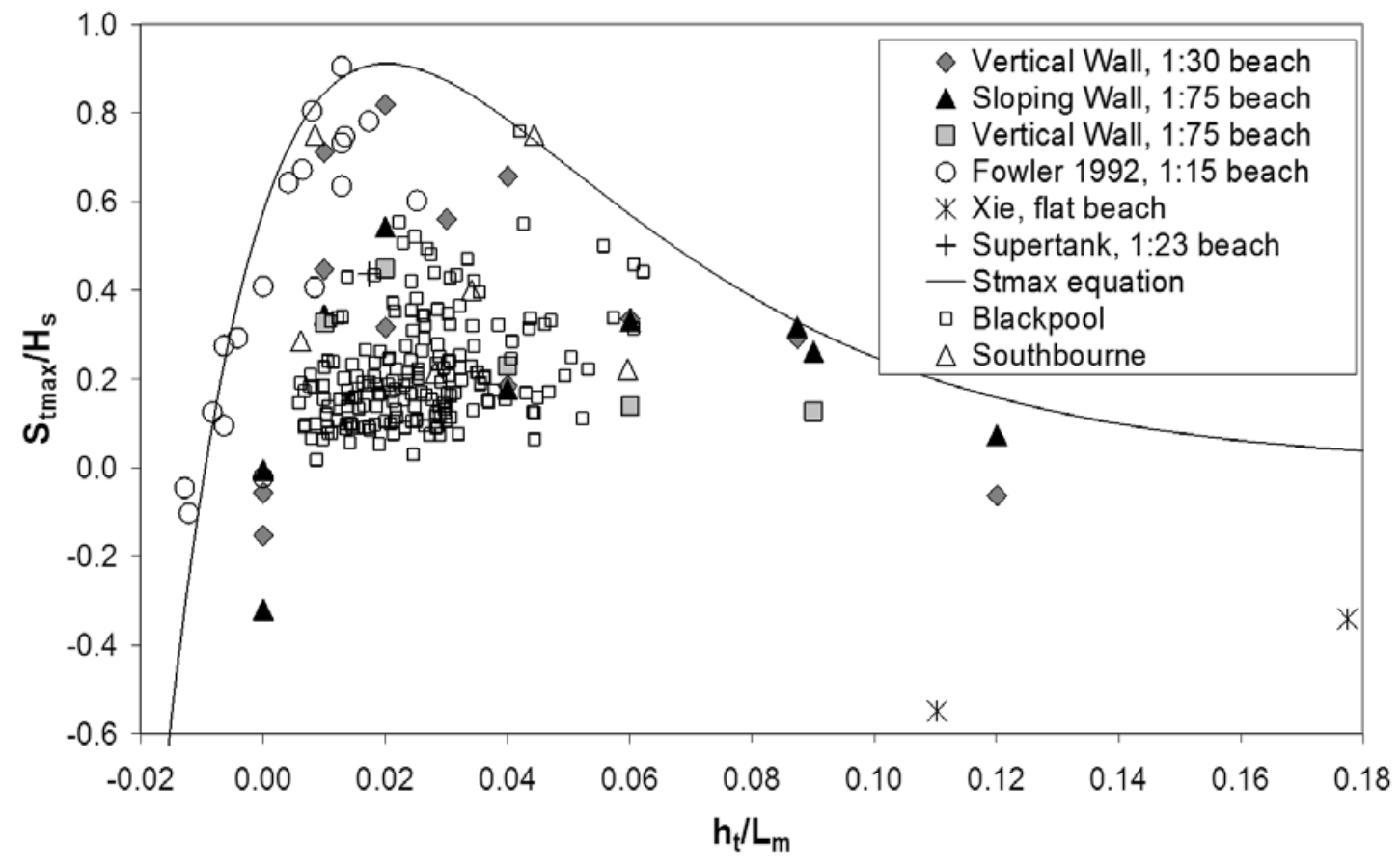

Figure 6: Envelope toe scour predictor - Equation (1): laboratory data and field data from Blackpool and Southbourne; after Sutherland et al (2008) 
It can be seen from Figure 6 that the scour depth is everywhere less than $H_{s}$, and that the peak scour depth occurs for relative water depths $\left(h_{t} / L_{m}\right)$ of around 0.01 to 0.02 and that the scour depth reduces for shallower and deeper water.

In situations where the beach slope is known then an alternative empirical equation for the depth of scour at the Toe of a vertical seawall developed using the laboratory data in Figure 6 can be used (HR Wallingford, 2008b; Sutherland et al, 2008). HR Wallingford (2008b) showed that the relative toe scour depth can be given with a beach slope dependency by:

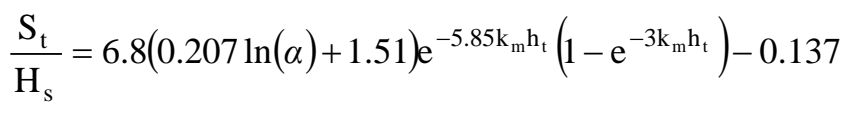

$$
\left[-0.04 \leq h_{t} / L_{m} \leq 0.12\right]
$$

where:

$S_{t}$ is the scour depth at the Toe of the structure $(m)$;

$\mathrm{H}_{\mathrm{s}}$ is the deep water (unbroken) significant wave height (m);

$\alpha$ is the beach slope (radians);

$\mathrm{k}_{\mathrm{m}}$ is the linear theory wavenumber $k_{m}=2 \pi / T_{m}(1 / \mathrm{s})$ with $T_{m}$ the mean wave period (s); and,

$h_{t}$ is the water depth above the sediment level at the Toe of the seawall $(m)$.

The range of validity of Equation (2) is given in the [] brackets. An extended version of this predictor including wave set up on the beach was also developed (Sutherland et al, 2008). Equation (2) was derived from tests with normally-incident irregular waves and beach slopes of 1:15, 1:30 and 1:75. The equation predicts maximum scour depth reducing with decreasing beach slope as seen in the laboratory data.

Both Equations (1) and (2) predict the scour after 3,000 waves (i.e. 6.7 hours for an 8 second period wave) and a correction must be used to predict scour for time intervals other than 3,000 waves.

\subsection{Prediction of toe scour at vertical seawalls with shingle beaches}

Scour depths in shingle beaches can be predicted using the parametric plot of Powell and Lowe (1994) reproduced as Figure 7 (also used by Whitehouse, 1998). This was based on an extensive set of laboratory tests conducted with normally-incident irregular waves that broke on a 1:7 slope shingle beach, with a vertical impermeable seawall. The maximum scour predicted was $1.5 \mathrm{H}_{\mathrm{s}}$. The method is valid for beach sediment in the range $5 \mathrm{~mm}<\mathrm{d}_{50}<30 \mathrm{~mm}$ (modelled at 1:17 scale).

Figure 7 shows contours of $S_{3000} / H_{s}$ plotted on a graph with axes of relative depth, $h_{t} / H_{s}$ and relative wave steepness, $H_{s} / L_{m}$, where:

- $h_{t} / H_{s}$ is the relative water depth;

- $h_{t}$ is the water depth above the sediment level at the Toe of the seawall $(\mathrm{m})$;

- $H_{s}$ is the deep water (unbroken) wave height (m);

- $H_{s} / L_{m}$ is the wave steepness;

- $L_{m}$ is the mean wavelength (as Equation (1)) (m); and,

a $S_{3000}$ is the scour depth after 3,000 waves. 


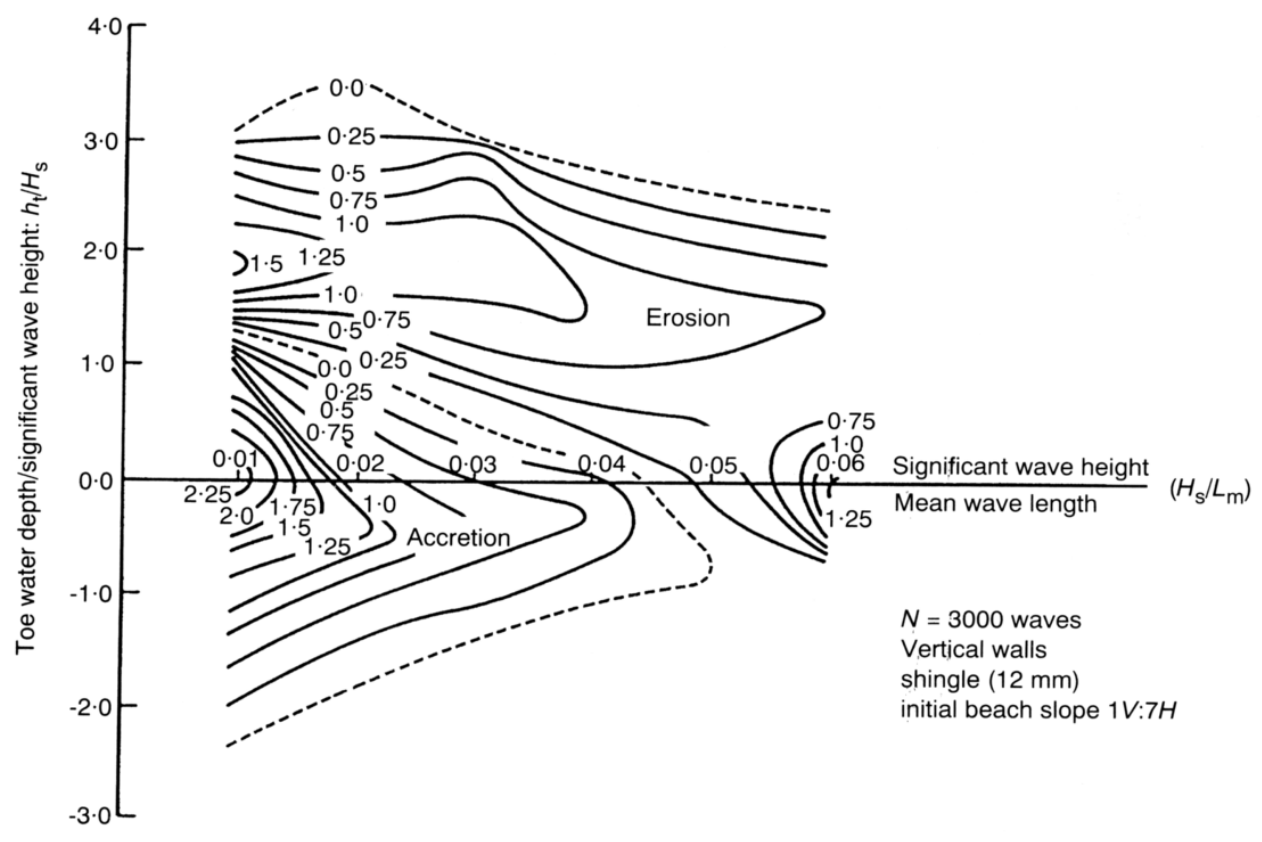

Figure 7: Prediction diagram for scour (erosion) and accretion at vertical seawalls with shingle beaches (Powell and Lowe, 1994) - contours of dimensionless scour depth S3000/Hs

The scour depth associated with a given water depth and wave condition is obtained by calculating the wave steepness $H_{s} / L_{m}$ and the dimensionless toe water depth $h_{t} / H_{s}$ and reading off the value of dimensionless scour depth $S_{3000} / H_{s}$. A correction for time intervals other than 3,000 waves is required (Powell and Lowe, 1994).

\section{Monitoring}

\subsection{Beach level and scour hole monitoring at the Toe}

Methods for measuring beach levels (and changes) were reviewed by Sutherland et al (2006), including measurements during the tide using scour monitors (e.g. Figure 8). If a long-term record of beach levels in front of a structure is available, such as the Environment Agency's twice yearly beach surveys carried out in Anglian Region for the last 10 years, then long-term trends in mean beach level in front of the structure and in intertidal beach volume can be calculated. If these values show a statistically significant decrease in mean beach level with time then existing trends can be projected forwards to identify when the structure may become vulnerable to the additional effect of local toe scour, should those trends continue.

The deployment of scour monitoring systems that remain on-site just in front of a structure (for weeks or longer) is one practical way of assessing the temporal variability of a beach surface including lowering and scour.

An array of scour monitors could be installed that looks for the bed lowering to the point at which short-term fluctuation from the time-dependent mean level could de-stabilise the asset ('trigger' level). The data can be recorded and analysed after recovery of the monitor or the data can be fed onshore through a cable to a data logger displaying the bed level; with an alarm mechanism if required. Analysis of the data for storm 
events can be used to confirm the predictions from the equations presented in this paper and real time data can be used to evaluate if the bed drops near to or below the trigger level. The monitoring could then take place a few times per year (at least twice) and a more detailed study or remedial action undertaken before the beach level drops below pre-determined values (or the 'trigger' level).

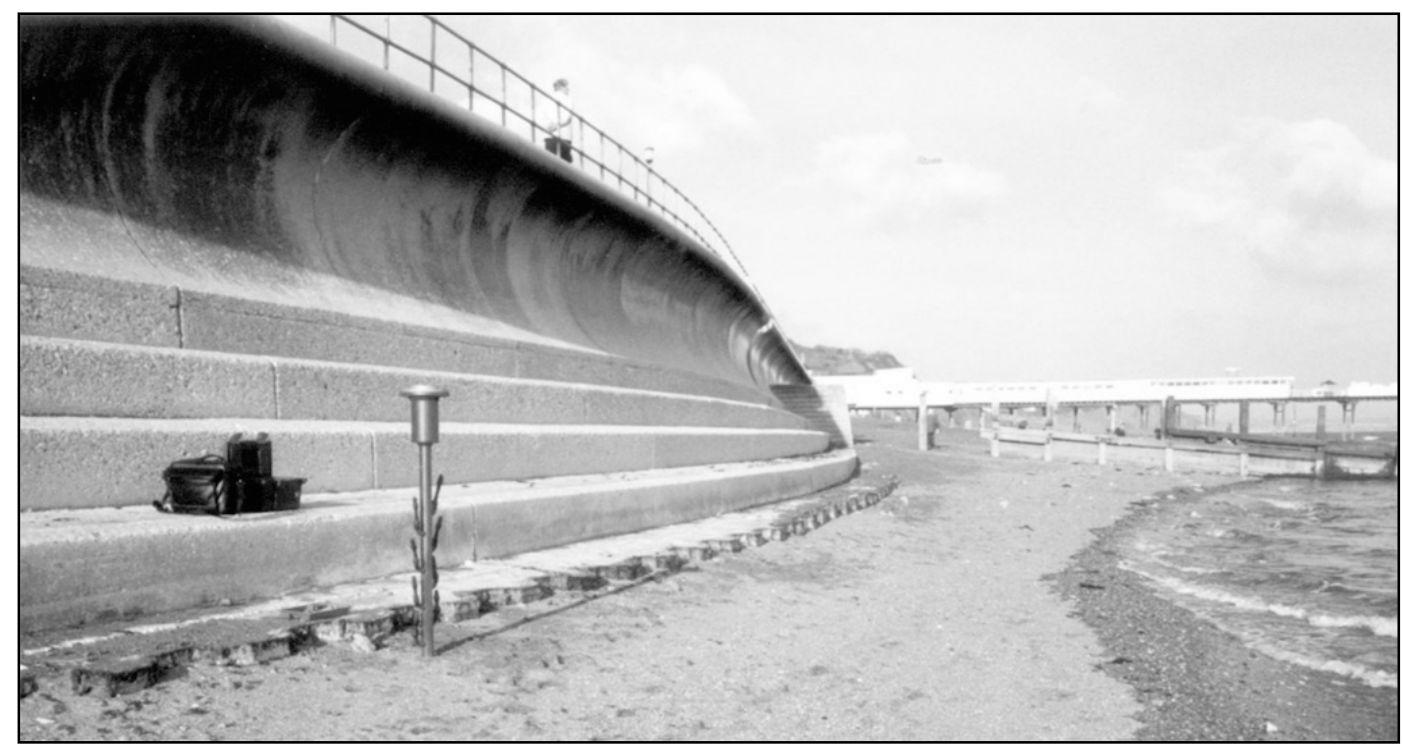

Figure 8: Scour monitor for recording changes in beach levels - beach at low level

\subsection{Structure condition monitoring}

Toe structure condition monitoring as part of a 'normal' condition inspection regime can be hampered by the fact that Toe structures are often unobserved because they are either submerged or below beach level at the time of the scheduled inspection. If the structure is thought not to be covered by sediment then an inspection can be scheduled for a time and date when the tide is low enough for it's inspection. Otherwise, if it is permanently covered by sediment, then there is rarely a requirement to inspect it anyway as sediment provides a protective covering. Inspection pits or trenches may be used if knowledge is required about the Toe structure or its configuration, especially for unknown foundations. One of the most frequent problems is the lack knowledge about the presence and depth of Toe structures, especially for older structures where engineering drawings have been lost or do not exist.

Consideration should be given to the inspection of ground beneath revetted or stepped Toe revetments to assess any washout of fill material. Installation of inspection access hatches, taking core samples, or installing holes for small camera probes could be prescribed for monitoring purposes.

A simple way by which an inspector could form a judgement about beach levels is to use a 'Plimsoll' type line painted or fitted to a seawall, or by 'dipping' - measuring the beach level from the structure itself. A fixed line can visually indicate beach height at the wall in relation to the Toe of the structure if it was measured in during construction or retrofitted. This can provide the asset manager with a datum to record information on beach level variability over time in an inexpensive and straight forward way. A pre-determined trigger level for beach height could be measured in such that when it was revealed and observed it would flag up the need for intervention. Monitoring localised responses in this way allows beach managers to be proactive in their maintenance programme and reduces the potential for damage. It also provides useful design information for future schemes. 


\section{Suggested predictive approach}

For each location being considered the engineer needs to determine a trigger level for intervention (i.e. the critical level on Figure 5). This will be based on key parameters related to structural performance, beach safety etc. Once this level has been set a simple assessment for any section of a structure can be determined (initially) on a seasonal, e.g. summer and winter 6-monthly basis, using the following eight steps:

1. Prescribe critical 'trigger' level for beach level at the Toe of the structure (see Figure 5 for definition actual line prescribed on a case by case basis);

2. Determine whether the beach in front of the structure is sand or shingle;

3. Is the beach slope known?

4. Estimate the lowest beach level at the structure for the next two seasons based on a linear trend and the variance of historic bed levels (unless a more sophisticated approach is warranted);

5. Determine the maximum water depth at the structure for the next two seasons based on predicted tide levels with allowance for surge;

6. Estimate the extreme wave conditions $\left(\mathrm{H}_{\mathrm{s}}\right.$ and $\left.\mathrm{T}_{\mathrm{m}}\right)$ for the next two seasons.

7. Predict the combined beach level and scour level; and,

8. Carry out condition grade assessment and monitoring as necessary to confirm the expected position of the beach level.

With the above information the following decision process is implemented:

1. If the beach is sand and the answer to 3. is "no" use Equation (1) to predict scour depth and if "yes" use Equation (2) to predict scour depth;

2. If the beach is shingle use a look up table based on Figure 7, or read directly off Figure 7, to predict scour depth;

3. Determine the combined beach level and scour depth for the next two seasons; and,

4. Evaluate whether this causes the beach level to drop below the critical level:

a. If it does not then reformulate on an ongoing basis the prediction for the next two seasons, updating the input parameters as appropriate based on site observations; or,

b. If it does then plan appropriate monitoring of structure condition and beach levels at more frequent intervals and implement mitigation / intervention plans.

If a more detailed assessment is required for a particular asset the predictions can be made more frequently, given the relevant input data. Case examples illustrating the approach are included in the Toe Structures Guide. With some further definition this approach can be implemented in a probabilistic assessment (HR Wallingford, 2008c). 


\section{Conclusions}

The following findings and recommendations form the conclusions of the paper which has presented some key issues related to the management of the Toe of coastal structures:

1. For risk-based asset management of coastal defences and Toe structures we need to combine condition grade assessments with monitoring and predictive approaches for beach levels and toe scour;

2. The monitoring and analysis of beach levels and assessment of structure condition provide essential information for predictive performance analysis.

3. A range of tools and methods are available to demonstrate applicability of the approach;

4. Some simple steps could help significantly with visual assessment (e.g. beach level height gage or 'Plimsoll' line placed on a seawall) facilitating early warning of beach levels;

5. Methods are available to assess beach lowering and predict scour hole depth. An approach for combining these two estimates of future bed level has been proposed which allows the evaluation of future levels against pre-determined critical beach levels; and,

6. Monitoring of short time scale (within tide) variability of scour holes or beach levels at the Toe is possible to check the predictions at a particular site.

\section{Acknowledgements}

The funding for the work described in this paper was provided by the Environment Agency R\&D programme. Dr James Sutherland of HR Wallingford and Dr Noel Beech (Independent) provided useful comments on a draft of this paper.

\section{References}

CIRIA. (1986). Seawalls: survey of performance and design practice. Tech Note 125, ISBN 086017 266X, ISSN 0305 - 1718.

HR Wallingford (2008a). Understanding the lowering of beaches in front of coastal defence structures, Stage 2 Technical Note 3. Defra/EA R\&D Project Record FD1927/PR3. Internet:http://sciencesearch.defra.gov.uk/Document.aspx?Document=FD1927 7463 PR.pdf (page accessed 27/02/2009).

HR Wallingford (2008b). Understanding the lowering of beaches in front of coastal defence structures, Stage 2 Technical Note 9. Defra/EA R\&D Project Record FD1927/PR9. Internet:http://sciencesearch.defra.gov.uk/Document.aspx?Document=FD1927 7469 PR.pdf (page accessed 27/02/2009).

HR Wallingford (2008c). Understanding the lowering of beaches in front of coastal defence structures, Stage 2 Technical Note 5. Defra/EA R\&D Project Record

FD1927/PR5. Internet:http://sciencesearch.defra.gov.uk/Document.aspx?Document=FD1927 7465 PR.pdf (page accessed 27/02/2009).

Larson, M., Capobianco, M., Jansen, H., Różyński, G., Southgate, H.N., Stive, M., Wijnberg, K.M. and Hulscher, S. (2003). Analysis and modelling of field data on coastal morphological evolution over yearly and 
decadal time scales. Part 1: Background and linear techniques. Journal of Coastal Research, 19(4) 760 775.

Markle, D.G. (1986). Stability of Toe Berm Armor Stone and Toe Buttressing Stone on Rubble-mound breakwaters and jetties; physical model investigation, Technical Report REMR-CO-12, U.S. Army Engineer Waterways Experiment station, Vicksburg, MS.

Patterson, P., Glennerster, M. and Millar, G. (2004). Corton Coast Protection. In: Proceedings of the $39^{\text {th }}$ Defra Flood and Coastal Management Conference, July 2004. Paper 06b-2.

Piling Handbook (2005). $8^{\text {th }}$ Edition, ARCELOR RPS.

Powell, K.A. and Lowe, J. P. (1994). The scouring of sediments at the toe of seawalls. In: Proceedings of the Hornafjordur International Coastal Symposium, Iceland - June 20-24. Edited by Gisli Viggosson - pp 749 to 755 .

Scott, C.R. (1969). An Introduction to Soil Mechanics and Foundations. Applied Science Publishers Ltd.

Sutherland, J., Brampton, A. and Whitehouse, R. (2006). Toe scour at seawalls: monitoring, prediction and mitigation. Paper 3b in Proceedings 41st Defra Flood \& Coastal Management Conference, The University of York., July 2006.

Sutherland, J., Brampton, A.H., Obrai, C., Dunn, S., and Whitehouse, R.J.W. (2008). Understanding the Lowering of Beaches in front of Coastal Defence Structures, Stage 2. R\&D Technical report FD1927/TR, Defra, London. Internet http://sciencesearch.defra.gov.uk/fip (page accessed: 27/02/2009)

Van Rijn, L.C. (1998). Principles of Coastal Morphology. Aqua Publications. ISBN 90-800356-3-7.

Whitehouse, R.J.S. (1998). Scour at Marine Structures. A Manual for Practical Applications. Thomas Telford. ISBN 0727726552. 